\title{
Geographic variation in the upper thermal limits of an intertidal snail: implications for climate envelope models
}

\author{
Evelyne S. L. Kuo ${ }^{1,2, *}$, Eric Sanford ${ }^{1,2}$ \\ ${ }^{1}$ Department of Evolution and Ecology, University of California, Davis, California 95616, USA \\ ${ }^{2}$ Bodega Marine Laboratory, Bodega Bay, California 94923, USA
}

\begin{abstract}
Although climate envelope models are used increasingly to predict the response of species to climate change, these models may perform poorly when species are comprised of locally adapted populations with differing environmental tolerances. Despite this concern, little is known about how tolerance traits vary across a species' geographic range. In this study, we tested whether the upper thermal limits of a direct-developing intertidal snail, Nucella canaliculata, varied among populations distributed along the northeastern Pacific coast. Snails from 7 sites in central California, northern California, and Oregon (USA) were reared through 2 generations in a common laboratory environment to minimize the potential influence of field acclimatization and other non-genetic effects. Laboratory assays of acute lethal temperature tolerance $\left(\mathrm{LT}_{50}\right)$ indicated that newly hatched $N$. canaliculata from central California were less heat tolerant than their conspecifics from Oregon. These differences in upper thermal limits likely have a genetic basis and are consistent with a mosaic of potential thermal stress in rocky intertidal habitats along the northeastern Pacific coast. In particular, some northern sites experience longer exposures to stressful midday low tides than southern sites, due to variation among regions in the timing of low tides. Persistent regional differences in tidal regimes, climate, and other environmental factors may act as selective forces that influence the physiology of intertidal species with broad latitudinal ranges. The resulting geographic distribution of thermally tolerant genotypes may be spatially complex, and may thus alter predictions regarding the effects of climate change on local extinctions and species' geographic range shifts.
\end{abstract}

KEY WORDS: Thermal tolerance · Thermal stress · Biogeography · Local adaptation · Climate change $\cdot$ Nucella $\cdot$ Rocky intertidal habitats

Resale or republication not permitted without written consent of the publisher

\section{INTRODUCTION}

As evidence of the ecological effects of climate change becomes increasingly apparent (Parmesan \& Yohe 2003, Parmesan 2006), 'climate envelope' models have emerged as a promising approach for predicting the response of species to ongoing changes in environmental conditions (Pearson \& Dawson 2003, Guisan \& Thuiller 2005). These models define a species' climate envelope either by correlating its current geographic distribution with contemporary climatic conditions, or by mechanistically determining its ecophysiology in relation to various environmental variables (Pearson \&
Dawson 2003, Hijmans \& Graham 2006). These requirements are then projected onto scenarios of future climate change to predict range expansions, range contractions, and extinction risks (Thomas et al. 2004, Araújo et al. 2006). In some cases, climate envelope approaches may fail to accurately predict responses to climate change, because these models neglect other non-climatic processes that can influence species' geographic distributions (Pearson \& Dawson 2003). Recent discussions suggest that an additional limitation of climate envelope models is that they assume that environmental tolerance is homogeneous throughout the geographic range of a species and thus 
ignore the existing adaptive differentiation of populations to local environmental conditions (Davis \& Shaw 2001, Harte et al. 2004). Although this information may be critical for correctly predicting local extinctions and range shifts in response to increasing global temperatures (Davis \& Shaw 2001, Harte et al. 2004, Aitken et al. 2008, O'Neill et al. 2008), little is known about how environmental tolerance traits vary among populations across a species' geographic range for most taxa (but see review by Savolainen et al. 2007).

Intertidal marine organisms are thought to be particularly vulnerable to global warming, because some of these species appear to be currently living near the edge of their upper thermal limits with little ability to further increase heat tolerance through acclimation (Stillman 2003, Somero 2005). However, studies of these animals have historically measured the physiological traits of individuals collected from one or a few locations, and it is unclear whether spatially separated populations have evolved differential tolerances to their varied local environments. Recently, intraspecific differences in physiological traits among populations have been compared over broad latitudinal scales (Sorte \& Hofmann 2004, Osovitz \& Hofmann 2005, Sagarin \& Somero 2006, Place et al. 2008). Although these studies have identified important macrophysiological variation among populations, it is unclear whether these phenotypic differences resulted from acclimatization to varied physical conditions, or whether genetically-based differences exist among geographically separated populations.

In this study, we examined whether geneticallybased differences in upper thermal limits exist among populations of the channeled dogwhelk Nucella canaliculata, an intertidal snail found along the Pacific coast of North America from central California to Alaska, USA (Sanford \& Worth 2009). This snail has direct development with crawl-away juveniles that hatch out from benthic egg capsules. Adults are restricted to wave-exposed habitats on rocky shores and rarely migrate across the sandy habitats that typically separate rocky headlands along the coast. The low dispersal potential of this species, resulting from its lack of a planktonic larval phase and restricted adult migration, is corroborated by molecular data indicating low gene flow among populations (Sanford et al. 2003). This restricted genetic exchange among $N$. canaliculata populations may allow spatial variations in selection to overcome the homogenizing effects of gene flow, resulting in adaptive genetic differentiation among local populations (Grosberg \& Cunningham 2001). Recent work has documented genetically-based differences in predation ability among populations of $N$. canaliculata (Sanford \& Worth 2009).
Coastlines are often characterized by strong latitudinal gradients in abiotic and biotic factors (Schoch et al. 2006). Although ambient water and air temperatures are generally expected to increase with decreasing latitude, Helmuth et al. $(2002,2006)$ showed that the body temperatures of the intertidal mussel Mytilus californianus do not vary monotonically with latitude along the northeastern Pacific coast. Instead, thermal stress in rocky intertidal habitats varies in a mosaic pattern along the coast depending on the timing of summer low tides at different locations: some northern 'hot spots' (Oregon and Washington) with extreme midday low tides in the summer are more thermally stressful than some southern sites (central California) where the lowest tides occur during the night.

Here, we hypothesized that geographic variation in thermal regimes along the northeastern Pacific coast has selected for genetic differences in the upper thermal limits of Nucella canaliculata populations originating from different regions. In particular, we predicted that $N$. canaliculata populations originating from hot spots with higher potential thermal stress (Oregon) have evolved greater tolerance of high temperatures than those from less thermally stressful sites (central California). To evaluate the intrinsic genetic differences in thermal tolerance among populations, snails were reared through 2 generations in the laboratory under a common garden environment to reduce the potential for non-genetic effects such as thermal history, maternal effects, and developmental plasticity to influence thermal tolerance. We focused on the upper thermal limits of newly hatched juvenile snails, because previous work has suggested that these early life stages are particularly vulnerable to environmental stress in Nucella and other intertidal invertebrates (Gosselin \& Chia 1995, Gosselin \& Qian 1997).

\section{MATERIALS AND METHODS}

Rearing F1 snails. We collected Nucella canaliculata egg capsules from 7 wave-exposed, rocky intertidal sites in 3 regions: central California $(n=2)$, northern California $(n=2)$, and Oregon $(n=3$; Fig. 1). These regions were known to differ in potential thermal stress (Helmuth et al. 2002), but sites within regions were selected haphazardly without specific knowledge of local thermal regimes. To standardize wave exposure, our collection areas were all surf-pounded, mid-intertidal beds of the mussel Mytilus californianus, with the sea palm Postelsia palmaeformis (an indicator of high wave exposure; Paine 1979) present at all sites except Strawberry Hill, Oregon. During May to August 2005, we visited each site and collected 7 to 8 independent sets of capsules from mussel bed 


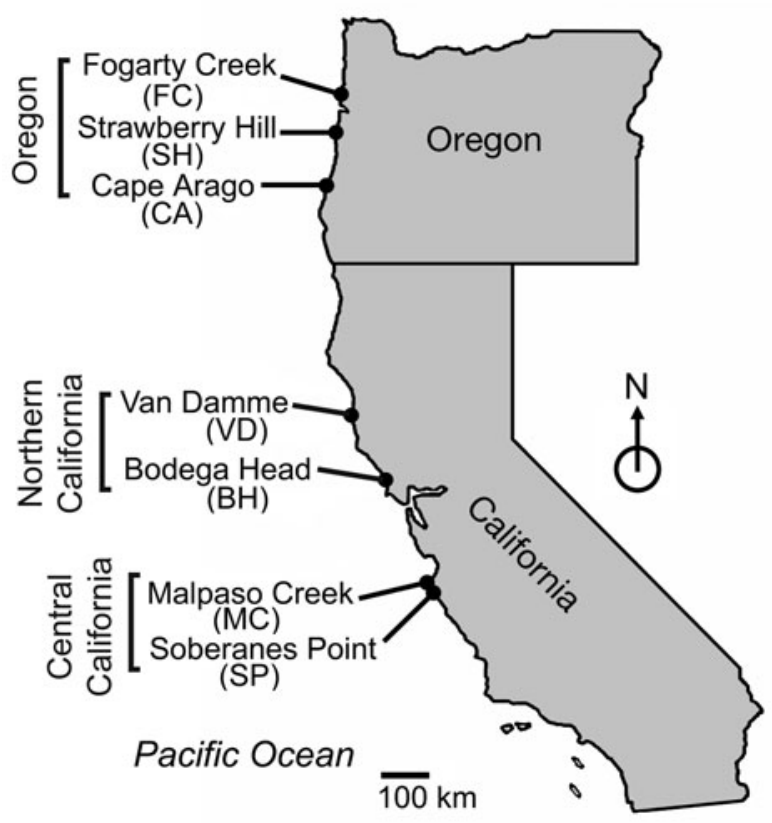

Fig. 1. Field sites for collection of Nucella canaliculata egg capsules

habitats at approximately $0.6 \mathrm{~m}$ above Mean Lower Low Water (MLLW) and from $>50 \mathrm{~m}$ of shore (to ensure that capsules were produced by different females). Capsules were placed in small containers with mesh sides (Perma Brew tea strainers, Upton Tea Imports) and were submerged in running seawater at Bodega Marine Laboratory until hatching occurred (June to October 2005). For each lineage (i.e. independent set of egg capsules), 50 hatchling snails (F1 generation) were haphazardly selected and transferred to a new mesh-sided strainer. Hatchlings were initially fed a diet of newly recruited 1 to $2 \mathrm{~mm}$ blue mussels $M$. trossulus. These small blue mussel recruits were obtained by sorting through clumps of juvenile $M$. trossulus that were collected regularly from the central Oregon coast. As juvenile snails grew, they were transferred to $1 \mathrm{l}$ containers and were fed progressively larger $M$. trossulus. To ensure that individuals did not mate with siblings, sexually immature snails were divided by sex during winter 2006 and transferred into 2 separate containers for each lineage (i.e. 1 for males, 1 for females).

Breeding F1 snails. F1 snails reached sexual maturity in approximately $9 \mathrm{mo}$, and within-population crosses were established in May 2006. Because snails were successfully raised to maturity from 6 to 8 independent sets of egg capsules from each of the 7 populations, we had a sufficient number of lineages to create 15 to 28 unique non-sibling crosses within each population. Each of these crosses was replicated 1 to 5 times for a total of around 40 breeding pairs per popu- lation (total $\mathrm{n}=274$ breeding pairs). Breeding pairs were randomly assigned to independent 1 l plastic containers arranged on indoor sea tables at Bodega Marine Laboratory. Each container received water from an independent water line inserted through the lid of the container. Snails were fed Mytilus trossulus and were maintained under a light schedule that changed monthly to match the ambient light schedule at Bodega Bay. Females attached egg capsules to the walls of the $1 \mathrm{l}$ containers, and these capsules were left in place during early development. Later in development, we transferred the capsules to mesh-sided strainers so that juvenile snails (F2 generation) would be contained after hatching. In the laboratory, the time between egg capsule production and hatching was approximately $10 \mathrm{wk}$.

The F1 breeding pairs started producing egg capsules in summer 2006. Some reproduced multiple times during the period from 2006 to 2008, and 54.7\% of the breeding pairs produced egg capsules that yielded at least some live hatchlings. The F2 hatchlings that were produced earlier (October 2006 to April 2007) were used in other experiments (Sanford \& Worth 2009), and juveniles from 49 lineages that hatched between June 2007 and September 2008 were used in this study. Thermal tolerance trials were conducted on 6 to 11 independent snail lineages from each population originating from northern California and Oregon. Trials were conducted on only 3 independent lineages from the 2 central California populations due to limited availability of egg capsules from these populations. All F1 and F2 snails were kept submerged throughout their lifetimes, and water temperatures in the sea tables were recorded at $30 \mathrm{~min}$ intervals by temperature dataloggers (TidbiT, Onset Computer).

Thermal tolerance trials on F2 snails. In laboratory trials, a thermal gradient between 28 and $38^{\circ} \mathrm{C}$ was established using a $180 \times 10 \times 6 \mathrm{~cm}(\mathrm{~L} \times \mathrm{W} \times \mathrm{H})$ aluminum bar with 1 end connected with tubing to a recirculating cool water bath and the other end warmed by an internal heater (Fig. 2). The temperatures of the water bath and heater were both maintained at set levels by electronic controllers and thus a stable thermal gradient was achieved along the length of the bar. The aluminum bar was drilled with 124 holes (31 lengthwise $\times 4$ widthwise) into which $2.0 \mathrm{ml}$ flat-top microcentrifuge tubes fit exactly. Within 3 to $7 \mathrm{~d}$ of hatching, F2 juvenile snails from 1 to 3 lineages were tested simultaneously during each trial. Prior to each trial, snails were inspected under a dissecting microscope, and only snails that appeared healthy and active were tested. For each snail lineage, 12 microcentrifuge tubes each containing 4 sibling snails submerged in fresh seawater were placed along the length of the aluminum bar. Although intertidal organisms are often 


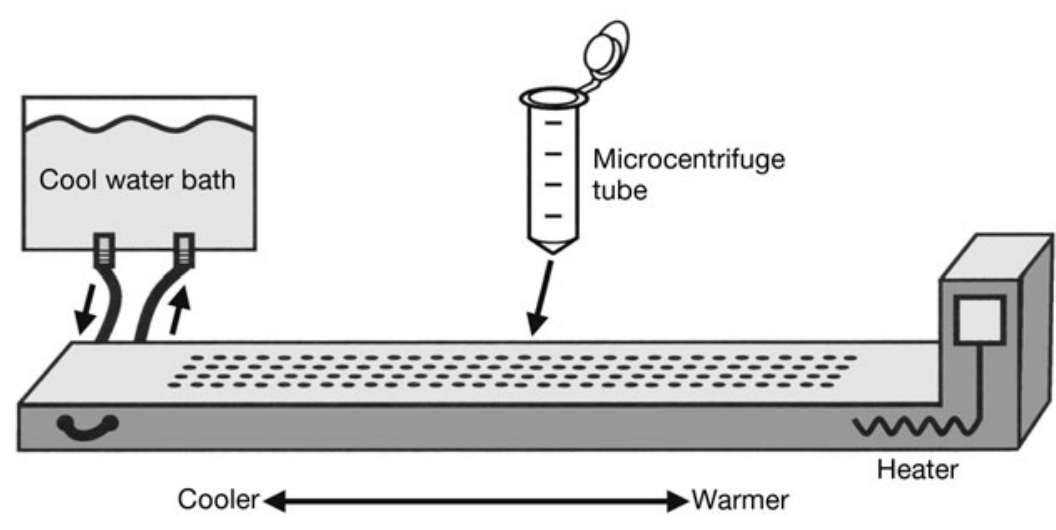

Fig. 2. Experimental setup for quantifying the upper thermal limits of juvenile snails in the laboratory. One end of an aluminum bar was connected to a cool water bath and the other end was connected to a heater to establish a stable thermal gradient $\left(28\right.$ to $\left.38^{\circ} \mathrm{C}\right)$ along the length of the bar. Hatchling snails were placed in microcentrifuge tubes that fit into rows of holes in the bar. See text for additional methods reflex (rapid and complete withdrawal into shell) upon stimulation by a sharp probe on the foot were scored as dead. Results from pilot studies confirmed that snails scored as dead under this protocol did not revive when given longer recovery periods. The shell lengths (from apex to siphonal canal) of all snails were measured with an ocular micrometer under a compound microscope.

Since juvenile snails hatched from egg capsules sporadically during the study period (June 2007 to September 2008), thermal tolerance trials were conducted over different seasons as hatchlings became available. As a result, minor variations in water temperatures in the weeks just prior to testing could have influenced the thermally stressed during aerial exposure, the thermal tolerance of intertidal organisms is generally quantified in water to avoid the confounding effects of desiccation on mortality (McMahon 1990, Tomanek \& Somero 1999, Stillman \& Somero 2000). A piece of mesh $(125 \mu \mathrm{m})$ was positioned at the upper third of each microcentrifuge tube to prevent snails from crawling to the air-water interface in the caps of the tubes and to eliminate the potential for evaporative cooling by the snails. A set of reference tubes containing only seawater was placed in holes alongside the experimental tubes containing the snails. Temperatures inside the tubes at each position along the bar were measured by inserting the thermocouple of a digital thermometer (Model HH502, Omega Engineering) through small holes punctured in the caps of the reference tubes.

Once the tubes were placed in the bar, each trial lasted $3 \mathrm{~h}$. Temperature was ramped up from ambient during the first $2 \mathrm{~h}$ and allowed to stabilize at the target temperature during the third hour. This time course was selected to approximate a realistic duration and trajectory of heating as recorded by intertidal temperature dataloggers placed at $0.7 \mathrm{~m}$ above MLLW at Strawberry Hill, Oregon, during 1996 to 1998 (E. Sanford unpubl. data). Temperatures in the reference tubes were measured repeatedly every 10 min during the last hour, and the maximum temperature recorded at each position was used for later analyses of the upper thermal limits (see 'Statistical analyses'). Following each trial, the microcentrifuge tubes containing the snails were immersed in flow-through seawater at ambient temperature during a $24 \mathrm{~h}$ recovery period. Snails were then inspected under a dissecting microscope, and individuals that did not exhibit an opercular thermal tolerances of hatchlings (e.g. via differential acclimation). To test this possibility, we analyzed whether the upper thermal limits of the snails varied as a function of the mean water temperatures of the sea tables during the $4 \mathrm{wk}$ prior to the laboratory trials (hereafter pre-trial water temperatures; see 'Statistical analyses').

Midday low tide exposure. We characterized the thermal regimes at the 7 collection locations using methods modified slightly from Helmuth et al. (2002). Nucella canaliculata have a fairly broad reproductive season that can vary among sites, but egg capsules can be found reliably at all 7 sites during June (E. Sanford unpubl. data). We therefore focused on conditions during the summer months (June to August), when hatchling snails are present at all sites. We calculated the cumulative hours of midday (10:00 to 14:00 h) exposure during summer low tides at 6 stations with available tidal predictions in the vicinity of our collection sites (within $20 \mathrm{~km}$ ) using the WWW Tide Predictor program (http://tbone.biol.sc.edu/tide/; Table 1). Tidal height predictions were calculated at 10 min intervals. Since the F1 snails used in this experiment emerged from egg capsules collected at $0.6 \mathrm{~m}$ above MLLW, estimates of all low tides with still tidal height below $0.6 \mathrm{~m}$ were included in this analysis. We used tidal predictions for the $25 \mathrm{yr}$ before the egg capsules were collected (1980 to 2004) to characterize the exposure to midday low tides encountered by $N$. canaliculata populations at their locations of origin.

Statistical analyses. For each thermal tolerance trial the proportion of dead snails at each temperature (the maximum temperature recorded at each position on a snail lineage, a logistic regression was fitted to 
Table 1. GPS coordinates of the field sites where Nucella canaliculata egg capsules were collected and of the locations of the tidal prediction stations in the vicinity of the collection sites

\begin{tabular}{|c|c|c|}
\hline Region & Collection site & Tidal prediction station \\
\hline Oregon & $\begin{array}{l}\text { Fogarty Creek (FC) } \\
44^{\circ} 50^{\prime} 16^{\prime \prime} \mathrm{N}, 124^{\circ} 03^{\prime} 33^{\prime \prime} \mathrm{W} \\
\text { Strawberry Hill (SH) } \\
44^{\circ} 15^{\prime} 00^{\prime \prime} \mathrm{N}, 124^{\circ} 06^{\prime} 55^{\prime \prime} \mathrm{W} \\
\text { Cape Arago (CA) } \\
43^{\circ} 18^{\prime} 13^{\prime \prime} \mathrm{N}, 124^{\circ} 24^{\prime} 07^{\prime \prime} \mathrm{W}\end{array}$ & $\begin{array}{l}\text { Depoe Bay } \\
44^{\circ} 48^{\prime} 36^{\prime \prime} \mathrm{N}, 124^{\circ} 03^{\prime} 29^{\prime \prime} \mathrm{W} \\
\text { Waldport, Alsea Bay } \\
44^{\circ} 25^{\prime} 59^{\prime \prime} \mathrm{N}, 124^{\circ} 04^{\prime} 00^{\prime \prime} \mathrm{W} \\
\text { Charleston, Coos Bay } \\
43^{\circ} 20^{\prime} 41^{\prime \prime} \mathrm{N}, 124^{\circ} 19^{\prime} 18^{\prime \prime} \mathrm{W}\end{array}$ \\
\hline Northern California & $\begin{array}{l}\text { Van Damme State Park (VD) } \\
39^{\circ} 16^{\prime} 43^{\prime \prime} \mathrm{N}, 123^{\circ} 48^{\prime} 12^{\prime \prime} \mathrm{W} \\
\text { Bodega Head (BH) } \\
38^{\circ} 19^{\prime} 09^{\prime \prime} \mathrm{N}, 123^{\circ} 04^{\prime} 28^{\prime \prime} \mathrm{W}\end{array}$ & $\begin{array}{l}\text { Mendocino, Mendocino Bay } \\
39^{\circ} 17^{\prime} 59^{\prime \prime} \mathrm{N}, 123^{\circ} 47^{\prime} 59^{\prime \prime} \mathrm{W} \\
\text { Bodega Harbor Entrance } \\
38^{\circ} 17^{\prime} 59^{\prime \prime} \mathrm{N}, 123^{\circ} 02^{\prime} 59^{\prime \prime} \mathrm{W}\end{array}$ \\
\hline Central California & $\begin{array}{l}\text { Malpaso Creek (MC) } \\
36^{\circ} 28^{\prime} 58^{\prime \prime} \mathrm{N}, 121^{\circ} 56^{\prime} 27^{\prime \prime} \mathrm{W} \\
\text { Soberanes Point (SP) } \\
36^{\circ} 26^{\prime} 50^{\prime \prime} \mathrm{N}, 121^{\circ} 55^{\prime} 44^{\prime \prime} \mathrm{W}\end{array}$ & $\begin{array}{l}\text { Carmel Cove, Carmel Bay } \\
36^{\circ} 31^{\prime} 00^{\prime \prime} \mathrm{N}, 121^{\circ} 55^{\prime} 59^{\prime \prime} \mathrm{W} \\
\text { Carmel Cove, Carmel Bay } \\
36^{\circ} 31^{\prime} 00^{\prime \prime} \mathrm{N}, 121^{\circ} 55^{\prime} 59^{\prime \prime} \mathrm{W}\end{array}$ \\
\hline
\end{tabular}

along the aluminum bar). The acute lethal temperature at which $50 \%$ of the snails died $\left(\mathrm{LT}_{50}\right)$ was estimated using the reverse prediction function (based on maximum likelihood estimates) in JMP (version 5.0, SAS Institute). A mixed model nested analysis of variance (ANOVA) was then used to test for differences in $\mathrm{LT}_{50}$ values among snail populations. Region (central California, northern California, and Oregon) was treated as a fixed effect, site nested within region [site(region)] was classified as a random effect, and the independent snail lineages were replicates within each site. The restricted maximum likelihood (REML) method in JMP was used for the ANOVA, since this method provides more reliable estimates of variance in unbalanced designs (Quinn \& Keough 2002). A Tukey HSD test on least-squares means was used for post hoc multiple comparisons among the 3 regions. Least-squares means were used due to unequal sample sizes.

Differences in shell lengths between dead and surviving snails in each snail lineage trial, and among snails from different source populations, were analyzed using $t$-tests and a 1-way ANOVA, respectively. Shell lengths were not significantly different between dead and surviving snails or among populations (see 'Results'); thus analysis of covariance (ANCOVA) using snail size as a covariate was not used in testing for differences in $\mathrm{LT}_{50}$ values among populations.

A 1-way ANOVA was used to test whether the 7 snail populations experienced different pre-trial water temperatures. Linear regressions were performed between the $\mathrm{LT}_{50}$ values of each independent snail lineage from the northern California and Oregon populations and their respective pre-trial water tempera- tures, to evaluate whether the hatchlings' upper thermal limits were correlated with water temperatures experienced during the $4 \mathrm{wk}$ prior to the laboratory trials. This analysis was not conducted for the 2 central California populations due to low replication $(\mathrm{n}=3)$.

The correlation between the $\mathrm{LT}_{50}$ values of the snail populations and the mean cumulative midday exposure at their locations of origin during the summer months was analyzed using a linear regression. Statistical analyses were not used to compare cumulative summer midday low tide exposure among sites because the values predicted for different years were temporally autocorrelated and not independent. We confirmed that the ANOVA assumptions of normality and homogeneity of variance were met in all analyses, and all statistical analyses were performed in JMP.

\section{RESULTS}

There were significant differences in the $\mathrm{LT}_{50}$ values of Nucella canaliculata originating from different regions $\left(F_{2,4}=7.34, p=0.046\right.$; Table 2, Fig. 3). Snails originating from central California were less heat tolerant than their conspecifics from Oregon (Tukey HSD, $p<0.05$ ), whereas the tolerances of northern California snails were intermediate and not significantly different from those of snails from the other 2 regions (Tukey

Table 2. Nucella canaliculata. Results of a mixed model nested ANOVA on the effects of region (fixed effect; central California, northern California, and Oregon) and sites nested within regions (random effect) on the upper thermal limits $\left(\mathrm{LT}_{50}\right)$ of $N$. canaliculata. In the restricted maximum likelihood (REML) method, the sum of squares (SS) for the tests on random effects refer to shrunken predictors rather than traditional estimates based on expected mean squares, thus there are no $F$ ratios and $\mathrm{p}$-values for Site(Region). df den: df denominator

\begin{tabular}{|lccccc|}
\hline Source & df & SS & MS & $\boldsymbol{F}$ & $\mathbf{p}$ \\
Model & 6 & 10.88 & 1.81 & 6.40 & $<0.0001$ \\
Error & 42 & 11.91 & 0.28 & & \\
& & & & & \\
Source & df & df den & SS & $\boldsymbol{F}$ & $\mathbf{p}$ \\
Region & 2 & 4 & 4.16 & 7.34 & 0.046 \\
Site(Region) & 4 & 42 & 2.44 & - & - \\
& & & & & \\
\hline
\end{tabular}




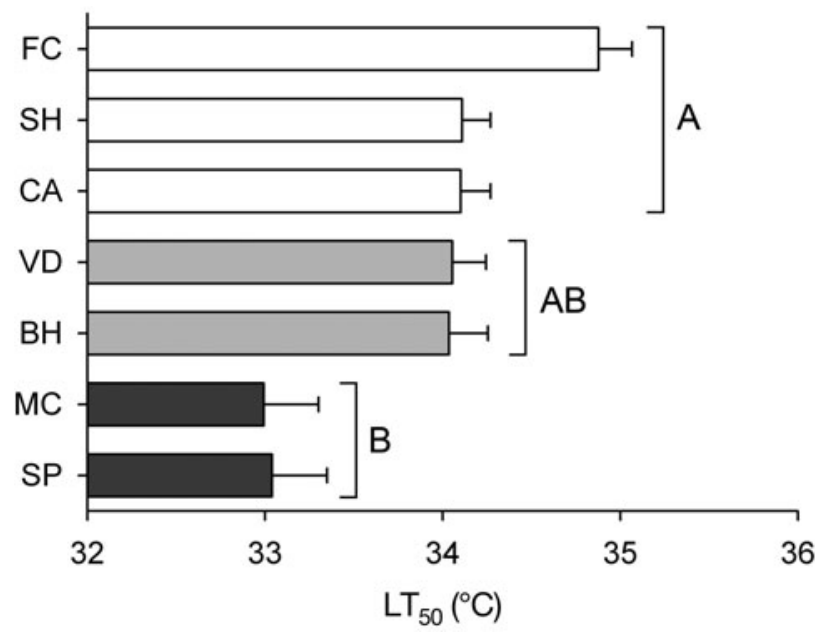

Fig. 3. Nucella canaliculata. Upper thermal limits (lethal temperature tolerance, $\mathrm{LT}_{50}$ ) of second-generation, laboratory-reared hatchlings. Bars represent the mean $( \pm 1 \mathrm{SE}) \mathrm{LT}_{50}$ values of independent snail lineages from each source population. Shared letters to the right of the bars indicate $\mathrm{LT}_{50}$ values that did not differ among regions (Tukey HSD, p > 0.05). Black, gray, and white bars represent populations from central California, northern California, and Oregon, respectively. Sites are arranged in order of latitude and are coded by the abbreviations shown in Fig. 1 with sample sizes (number of lineages) as follows: $\mathrm{SP}=3, \mathrm{MC}=3, \mathrm{BH}=6, \mathrm{VD}=8$,

$$
\mathrm{CA}=10, \mathrm{SH}=11, \mathrm{FC}=8
$$

HSD, $\mathrm{p}>0.05)$. Region and site(region) explained $24.02 \%$ and $21.48 \%$ of the variance in the $\mathrm{LT}_{50}$ values, respectively. The shell lengths of dead and surviving $N$. canaliculata did not differ in any thermal tolerance trial ( $t$-tests, $\mathrm{p}>0.05$ ) or among populations (ANOVA, $\left.F_{6,42}=1.91, \mathrm{p}=0.10\right)$.

The mean water temperatures of the sea tables during the $4 \mathrm{wk}$ prior to the laboratory trials varied between 9.69 and $13.63^{\circ} \mathrm{C}$ (mean \pm SE $=12.20 \pm$ $0.02^{\circ} \mathrm{C}$ ). Snail populations tested did not experience different pre-trial water temperatures (ANOVA, $F_{6,42}=$ $0.50, \mathrm{p}=0.80$ ). Moreover, within snail populations, there was no evidence that $\mathrm{LT}_{50}$ values were correlated with pre-trial water temperatures (separate regressions for all populations from northern California and Oregon; $\mathrm{p}>0.05)$.

Consistent with findings by Helmuth et al. (2002, 2006), patterns of tidal exposure varied among the 3 regions. During the summer months when hatchling snails are present, sites in Oregon had longer cumulative durations of exposure to midday low tides compared to sites in northern and central California (Fig. 4). However, the relationship between the $\mathrm{LT}_{50}$ values of the snail populations and the cumulative exposure to summer midday low tides at their locations of origin was not significant (linear regression, $\mathrm{p}=0.33)$.

\section{DISCUSSION}

\section{Genetic basis of differential thermal tolerance}

Our results demonstrated that upper thermal limits differed significantly among populations of Nucella canaliculata, and counter-intuitively, snails from central California were less heat tolerant than their conspecifics from higher-latitude populations (Oregon). These intraspecific differences likely have a genetic basis, because thermal tolerance was quantified in snails reared in a common laboratory environment through 2 generations. Moreover, both F1 and F2 snails were kept submerged throughout their lifetimes, thereby eliminating prior exposure to periods of thermal stress that might induce plastic variations in the thermal tolerance of the snails. There was no evidence that $\mathrm{LT}_{50}$ values were related to variation in pre-trial water temperature in the laboratory, and indeed these temperatures varied relatively little in this study. Thus, we assume that differential acclimation by the hatchling snails had minimal influence on the thermal tolerances of snails tested on different dates. An additional assumption of our study (and most common garden experiments) is that environmental conditions at Bodega Marine Laboratory did not induce patterns of genetically-based phenotypic variation different from those present in nature (Kawecki \& Ebert 2004).

Although genetically-based differences in growth rates are known to occur among populations of some marine invertebrates and fishes (Levinton \& Monahan 1983, Lonsdale \& Levinton 1985, Conover et al. 2006), this study is among the first to report intraspecific dif-

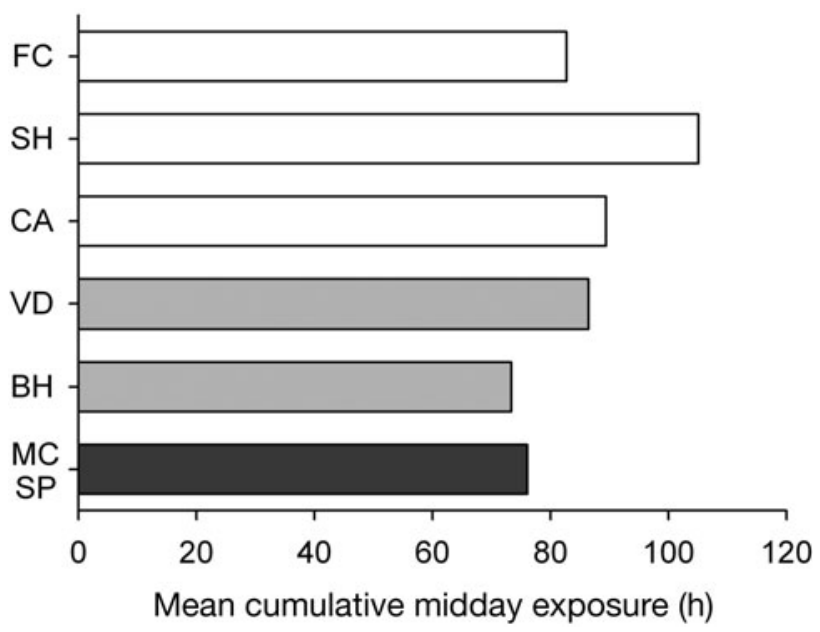

Fig. 4. Cumulative hours of midday (10:00 to 14:00 h) exposure during summer (June to August) low tides at the 7 Nucella canaliculata source locations (see Fig. 1). Data are mean values for the period from 1980 to 2004, based on still tidal height predictions from 6 nearby stations (see Table 1). Sites are coded by the abbreviations shown in Fig. 1 
ferences in the upper thermal limits of a marine organism that appear to be genetically based. Previous work has documented variations in temperature tolerance among populations of marine species (Clarke et al. 2000, Sokolova et al. 2000, Davenport \& Davenport 2005, Fangue et al. 2006), but most of these studies were not designed to distinguish between phenotypic plasticity and genetic differentiation. Although some of these studies inferred genetic differentiation among populations based on life history traits and molecular data, or held field-collected animals in the laboratory to standardize acclimation (Sokolova et al. 2000, Fangue et al. 2006), the potential influence of maternal effects or irreversible, non-genetic developmental plasticity could not be eliminated (Kinne 1964). To date, other studies that have reared animals through multiple generations under common garden environments to test for a genetic basis in differential temperature tolerance have used terrestrial insects such as fruit flies (Drosophila spp.; reviewed by Hoffmann et al. 2003b) and the pitcher-plant mosquito Wyeomyia smithii (Bradshaw et al. 2004).

\section{Latitudinal variation in intertidal thermal stress and tolerance}

Helmuth et al. $(2002,2006)$ observed that thermal stress on intertidal organisms does not increase as a simple function of decreasing latitude. Instead, the timing of extreme low tides relative to midday hours varies geographically in a complex manner such that some northern locations (e.g. Oregon) can be more thermally stressful than more southern sites (e.g. central California). We propose an extension of this finding and hypothesize that selection imposed by persistent variation in tidal regimes and thermal stress may leave an evolutionary signature on the thermal tolerance of some intertidal organisms. This may help to explain the counter-intuitive pattern observed in this study, in which Nucella canaliculata originating from more northerly locations (Oregon) were more tolerant of high temperatures than conspecifics from the more southerly sites (central California).

Our analysis of tidal predictions confirmed that, for the intertidal height relevant to Nucella canaliculata, some northern locations (Oregon) experience longer summer midday low tide exposure than those in central California. However, the overall correlation between the upper thermal limits of the snail populations and the predicted cumulative midday exposure at their locations of origin was non-significant. Clearly, timing of low tide exposure is only one of many environmental factors that contribute to variation in thermal stress among sites. Other factors such as air temperature, solar radiation, substrate angle, wave splash, and fog may also modify local conditions to determine the thermal stress experienced by organisms in the field (Helmuth et al. 2006). Geographic variation in potential thermal stress experienced by intertidal mussels has been estimated using a biophysical model that combines an energy balance equation with data from terrestrial meteorological stations, marine buoys, satellite observations, and tidal predictions (Gilman et al. 2006). An analogous model could be developed in the future to estimate regional variation in the body temperature of intertidal snails. Ideally, this model would also incorporate the potential effect of behavioral thermoregulation, because unlike sessile species such as mussels, mobile snails may seek thermal refuges to avoid stressful conditions (e.g. Garrity 1984).

Although a more complete characterization of thermal regimes experienced by our study populations is needed, our results are consistent with recent studies indicating that thermal stress on intertidal organisms may be more pronounced in Oregon than in central California (Helmuth et al. 2002, Sagarin \& Somero 2006). For example, Sagarin \& Somero (2006) surveyed 20 sites between Baja California, Mexico, and Vancouver Island, Canada, and found peak values of inducible heat-shock protein (Hsp70) expression in the congeneric snail Nucella ostrina and the mussel Mytilus californianus in central Oregon (around $45^{\circ} \mathrm{N}$ latitude), and reduced Hsp70 expression in both species between central California and southern Oregon. In contrast, Sorte \& Hofmann (2004) found significantly higher levels of Hsp70 expression in N. canaliculata collected from central California (Piedras Blancas and Soberanes Point) compared to those collected from central Oregon (Strawberry Hill and Fogarty Creek), suggesting that central California snails were more physiologically stressed than central Oregon snails.

These discrepancies between the heat-shock protein studies may be due to different sampling months when the organisms were collected from the field. Sorte \& Hofmann (2004) collected Nucella canaliculata from central California in April 2003 and from Oregon in May 2003, whereas Sagarin \& Somero (2006) collected N. ostrina and Mytilus californianus from central California in June 2000 and from Oregon in May 2000. During the spring (March to May), central California sites have longer exposure to midday low tides than sites in Oregon, but the pattern reverses in the summer (June to August) when Oregon sites have longer midday low tide exposure. This pattern is corroborated by temperature dataloggers deployed by Helmuth et al. (2006) that recorded maximum temperatures in central California in April and central Oregon in July. Heat- 
shock protein expression has been shown to exhibit high plasticity based on an organism's thermal history, usually reflecting the level of heat stress encountered by the individual prior to collection (Buckley et al. 2001, Osovitz \& Hofmann 2005). It is therefore possible that organisms in central California expressed higher levels of Hsp than their counterparts from Oregon during spring (when Sorte \& Hofmann [2004] collected their samples), while organisms in Oregon expressed higher levels of Hsp than organisms in California during the summer (when Sagarin \& Somero [2006] conducted their surveys). These considerations highlight the complexity of characterizing geographic and seasonal variations in thermal stress.

\section{Implications for predicted impacts of climate change}

Our study adds to the growing body of empirical evidence, primarily from terrestrial systems, cautioning against the assumption that species have homogeneous physiological traits throughout their ranges (Davis \& Shaw 2001, Aitken et al. 2008, O'Neill et al. 2008). Understanding how environmental stress tolerances vary among populations is especially important for predicting the effects of climate change on species comprised of populations that are locally adapted to abiotic conditions. For these species, subpopulations will likely be able to persist under only a portion of the full range of environmental conditions experienced by the species as a whole. Therefore, models that define a species' climate envelope using current distribution data may underestimate climate change effects on locally adapted species, because the climate envelopes of individual populations are narrower than that of the entire species (Harte et al. 2004, Aitken et al. 2008). Meanwhile, mechanistic models that define a species' climate envelope using physiological measurements derived from individuals from one or a few populations may underestimate extinction risk if these organisms originated from more stress-tolerant populations, and vice versa (Kearney \& Porter 2004, O'Neill et al. 2008).

Although some have recognized the importance of heterogeneous tolerances among populations across a species' range (Davis \& Shaw 2001, Harte et al. 2004, Aitken et al. 2008, O'Neill et al. 2008), a common expectation based on a simple latitudinal temperature gradient is that populations from low latitudes will be the most thermally tolerant due to local adaptation to warmer conditions (Davis \& Shaw 2001, Aitken et al. 2008). However, thermal stress can vary non-linearly with latitude in intertidal habitats (Helmuth et al. 2002, 2006), and our data suggest that the upper thermal limits of Nucella canaliculata can also vary among geo- graphically separated populations in a complex manner. In particular, snails originating from the southern range edge (central California) were the least tolerant of high temperatures, whereas populations from higher latitudes (Oregon) were more warm-adapted. A non-monotonic distribution of thermally tolerant genotypes among genetically differentiated populations along a latitudinal gradient may alter our predictions of climate change effects on the extinction risks of populations distributed in different parts of the species' range.

In response to global warming, extinction risks are generally expected to be highest at the rear edge (low latitude locations) of a species' geographic range (Davis \& Shaw 2001, Parmesan 2006, Aitken et al. 2008). However, Helmuth et al. (2002) suggested that episodes of mortality of intertidal organisms will be more likely at some northern 'hot spots' well within the species' range, rather than at low latitudes, due to the mosaic pattern of thermal stress along the coast. Results from this study further suggest that in the near term, species like Nucella canaliculata may be less vulnerable to localized mortality events due to evolutionary adaptation to current conditions, compared to broadly-dispersing species like the mussel Mytilus californianus, which have little genetic differentiation among populations (Addison et al. 2008). However, if thermal stress conditions exceed the limits of evolutionary adaptation (Hoffmann et al. 2003a), or if the rate of global warming outpaces the rate of evolutionary change in thermal tolerance (Etterson \& Shaw 2001, Aitken et al. 2008), N. canaliculata populations in northern hot spots will also become susceptible. Moreover, if the spatial extent of mortality events was large relative to the maximum dispersal distance of $N$. canaliculata, a rescuing effect by dispersal from other populations might be impeded, resulting in more persistent local extinction (Helmuth et al. 2006). M. californianus, on the other hand, has high population connectivity and could potentially recolonize the temporary extirpated areas with propagules from populations in 'cold spot' refugia. Even if the hot spots were colonized by dispersers from other $N$. canaliculata populations, the source of these colonizers would be critical for population persistence at these locations. Whereas the dispersal of warmadapted genotypes to these areas might be beneficial, colonization of the hot spots by less thermally tolerant individuals adapted to cold spots might be maladaptive (Aitken et al. 2008). Given these considerations, increased attention to the geographic distribution of environmental tolerance traits will likely improve our ability to predict the effects of climate change on species with diverse life histories and dispersal potentials. 
Acknowledgements. We thank D. J. Worth and J. L. Sones for laboratory help, G. N. Somero for loan of equipment, B. Helmuth for advice on tidal prediction calculations, J. W. White for statistical advice, and J. S. Clegg, B. P. Gaylord, M. W. Kelly, J. G. Morin, R. H. Seeley, J. L. Sones, D. S. Swezey, and 4 anonymous reviewers for helpful comments on this manuscript. This research was supported by a Croucher Foundation Scholarship (Hong Kong) to E.S.L.K. and NSF grant OCE06-22924 to E.S. This is contribution number 2458 of the Bodega Marine Laboratory, University of California, Davis, USA.

\section{LITERATURE CITED}

Addison JA, Ort BS, Mesa KA, Pogson GH (2008) Range-wide genetic homogeneity in the California sea mussel (Mytilus californianus): a comparison of allozymes, nuclear DNA markers, and mitochondrial DNA sequences. Mol Ecol 17: 4222-4232

Aitken SN, Yeaman S, Holliday JA, Wang T, Curtis-McLane S (2008) Adaptation, migration or extirpation: climate change outcomes for tree populations. Evol Appl 1:95-111

Araújo MB, Thuiller W, Pearson RG (2006) Climate warming and the decline of amphibians and reptiles in Europe. J Biogeogr 33:1712-1728

Bradshaw WE, Zani PA, Holzapfel CM (2004) Adaptation to temperate climates. Evolution 58:1748-1762

Buckley BA, Owen ME, Hofmann GE (2001) Adjusting the thermostat: The threshold induction temperature for the heat-shock response in intertidal mussels (genus Mytilus) changes as a function of thermal history. J Exp Biol 204: 3571-3579

Clarke AP, Mill PJ, Grahame J, McMahon RF (2000) Geographical variation in heat coma temperatures in Littorina species (Mollusca: Gastropoda). J Mar Biol Assoc UK 80: 855-863

Conover DO, Clarke LM, Munch SB, Wagner GN (2006) Spatial and temporal scales of adaptive divergence in marine fishes and the implications for conservation. J Fish Biol 69: $21-47$

Davenport J, Davenport JL (2005) Effects of shore height, wave exposure and geographical distance on thermal niche width of intertidal fauna. Mar Ecol Prog Ser 292:41-50

> Davis MB, Shaw RG (2001) Range shifts and adaptive responses to quaternary climate change. Science 292: 673-679

Etterson JR, Shaw RG (2001) Constraint to adaptive evolution in response to global warming. Science 294:151-154

Fangue NA, Hofmeister M, Schulte PM (2006) Intraspecific variation in thermal tolerance and heat shock protein gene expression in common killifish, Fundulus heteroclitus. J Exp Biol 209:2859-2872

> Garrity SD (1984) Some adaptations of gastropods to physical stress on a tropical rocky shore. Ecology 65:559-574

Gilman SE, Wethey DS, Helmuth B (2006) Variation in the sensitivity of organismal body temperature to climate change over local and geographic scales. Proc Natl Acad Sci USA 103:9560-9565

Gosselin LA, Chia FS (1995) Characterizing temperate rocky shores from the perspective of an early juvenile snail: the main threats to survival of newly hatched Nucella emarginata. Mar Biol 122:625-635

- Gosselin LA, Qian PY (1997) Juvenile mortality in benthic marine invertebrates. Mar Ecol Prog Ser 146:265-282

Grosberg R, Cunningham CW (2001) Genetic structure in the sea from populations to communities. In: Bertness MD,
Gaines SD, Hay ME (eds) Marine community ecology. Sinauer Associates, Sunderland, MA, p 61-84

Guisan A, Thuiller W (2005) Predicting species distributions: offering more than simple habitat models. Ecol Lett 8: 993-1009

Harte J, Ostling A, Green JL, Kinzig A (2004) Climate change and extinction risk. Nature 430, doi:10.1038/nature02718

Helmuth B, Harley CDG, Halpin PM, O'Donnell M, Hofmann GE, Blanchette CA (2002) Climate change and latitudinal patterns of intertidal thermal stress. Science 298: 1015-1017

- Helmuth B, Broitman BR, Blanchette CA, Gilman S and others (2006) Mosaic patterns of thermal stress in the rocky intertidal zone: implications for climate change. Ecol Monogr 76:461-479

> Hijmans RJ, Graham CH (2006) The ability of climate envelope models to predict the effect of climate change on species distributions. Glob Change Biol 12:2272-2281

- Hoffmann AA, Hallas RJ, Dean JA, Schiffer M (2003a) Low potential for climatic stress adaptation in a rainforest Drosophila species. Science 301:100-102

Hoffmann AA, Sørensen JG, Loeschcke V (2003b) Adaptation of Drosophila to temperature extremes: bringing together quantitative and molecular approaches. J Therm Biol 28: 175-216

Kawecki TJ, Ebert D (2004) Conceptual issues in local adaptation. Ecol Lett 7:1225-1241

Kearney M, Porter WP (2004) Mapping the fundamental niche: physiology, climate, and the distribution of a nocturnal lizard. Ecology 85:3119-3131

Kinne O (1964) Non-genetic adaptation to temperature and salinity. Helgol Mar Res 9:433-458

Levinton JS, Monahan RK (1983) The latitudinal compensation hypothesis: growth data and a model of latitudinal growth differentiation based upon energy budgets. II. Intraspecific comparisons between subspecies of Ophryotrocha puerilis (Polychaeta: Dorvilleidae). Biol Bull (Woods Hole) 165:699-707

> Lonsdale DJ, Levinton JS (1985) Latitudinal differentiation in copepod growth: an adaptation to temperature. Ecology 66:1397-1407

McMahon RF (1990) Thermal tolerance, evaporative water loss, air-water oxygen consumption and zonation of intertidal prosobranchs: a new synthesis. Hydrobiologia 193: 241-260

O'Neill GA, Hamann A, Wang T (2008) Accounting for population variation improves estimates of the impact of climate change on species' growth and distribution. J Appl Ecol 45:1040-1049

> Osovitz CJ, Hofmann GE (2005) Thermal history-dependent expression of the hsp70 gene in purple sea urchins: biogeographic patterns and the effect of temperature acclimation. J Exp Mar Biol Ecol 327:134-143

Paine RT (1979) Disaster, catastrophe, and local persistence of the sea palm Postelsia palmaeformis. Science 205:685-687

Parmesan C (2006) Ecological and evolutionary responses to recent climate change. Annu Rev Ecol Evol Syst 37:637-669

Parmesan C, Yohe G (2003) A globally coherent fingerprint of climate change impacts across natural systems. Nature 421:37-42

$>$ Pearson RG, Dawson TP (2003) Predicting the impacts of climate change on the distribution of species: Are bioclimate envelope models useful? Glob Ecol Biogeogr 12:361-371

> Place SP, O'Donnell MJ, Hofmann GE (2008) Gene expression in the intertidal mussel Mytilus californianus: physiological response to environmental factors on a biogeographic scale. Mar Ecol Prog Ser 356:1-14 
Quinn GP, Keough MJ (2002) Experimental design and data analysis for biologists. Cambridge University Press, Cambridge

Sagarin RD, Somero GN (2006) Complex patterns of expression of heat-shock protein 70 across the southern biogeographical ranges of the intertidal mussel Mytilus californianus and snail Nucella ostrina. J Biogeogr 33: 622-630

Sanford E, Worth DJ (2009) Genetic differences among populations of a marine snail drive geographic variation in predation. Ecology (in press)

Sanford E, Roth MS, Johns GC, Wares JP, Somero GN (2003) Local selection and latitudinal variation in a marine predator-prey interaction. Science 300:1135-1137

Savolainen O, Pyhäjärvi T, Knürr T (2007) Gene flow and local adaptation in trees. Annu Rev Ecol Evol Syst 38: 595-619

Schoch GC, Menge BA, Allison G, Kavanaugh M, Thompson SA, Wood SA (2006) Fifteen degrees of separation: latitudinal gradients of rocky intertidal biota along the California Current. Limnol Oceanogr 51:2564-2585

Sokolova IM, Granovitch AI, Berger VJ, Johannesson K (2000) Intraspecific physiological variability of the gastropod Littorina saxatilis related to the vertical shore

Editorial responsibility: Hans Heinrich Janssen, Oldendorf/Luhe, Germany gradient in the White and North Seas. Mar Biol 137: 297-308

Somero GN (2005) Linking biogeography to physiology: evolutionary and acclimatory adjustments of thermal limits. Front Zool 2:1, doi:10.1186/1742-9994-2-1

Sorte CJB, Hofmann GE (2004) Changes in latitudes, changes in aptitudes: Nucella canaliculata (Mollusca: Gastropoda) is more stressed at its range edge. Mar Ecol Prog Ser 274: $263-268$

Stillman JH (2003) Acclimation capacity underlies susceptibility to climate change. Science 301:65

Stillman JH, Somero GN (2000) A comparative analysis of the upper thermal tolerance limits of eastern Pacific porcelain crabs, genus Petrolisthes: influences of latitude, vertical zonation, acclimation, and phylogeny. Physiol Biochem Zool 73:200-208

Thomas CD, Cameron A, Green RE, Bakkenes M and others (2004) Extinction risk from climate change. Nature 427: $145-148$

Tomanek L, Somero GN (1999) Evolutionary and acclimationinduced variation in the heat-shock responses of congeneric marine snails (genus Tegula) from different thermal habitats: implications for limits of thermotolerance and biogeography. J Exp Biol 202:2925-2936

Submitted: January 20, 2009; Accepted: May 11, 2009

Proofs received from author(s): July 27, 2009 